\title{
TWO NEW SPECIES OF EXOTIC ANTS ${ }^{1}$
}

\author{
By ROBERT E. GREgG \\ Department of Biology, University of Colorado
}

The new forms described below were sent to me through the generosity of Dr. William L. Brown, Jr., and belong to the collections of the Museum of Comparative Zoology. I am indebted to Dr. Brown not only for the opportunity of describing and figuring these specimens, but for checking references and for comparing them with related species of ants in the Wheeler Collection.

\section{Stictoponera posteropsis $\mathrm{n}$. sp.}

Female. Length, $5.25 \mathrm{~mm}$., cephalic index, .80.

Head, excluding the mandibles, considerably longer than broad, the widest portion about midway between the mandibular insertions and the posterior corners; sides somewhat convex anterior to the eyes. Occipital border deeply and broadly concave, with sharp, upturned margin, and produced at the angles into pronounced occipital lobes which project upward. Clypeus rounded, convex, and with anterior margin entire. Frontal carinae remote, parallel, and possessing well developed lateral lobes covering the insertions of the antennae. Eyes very convex, almost hemispherical, set far back on the head in depressions just anterior to the occipital lobes; ocelli also far posterior on the head. Antennae 12-segmented; scapes long, nearly straight, increasing slightly in diameter toward the tips, and slightly surpassing the occipital lobes. Funiculi not clubbed, but segments gradually increasing in size, the terminal segment equal in length to the two preceding. Mandibles triangular; external border sinuate, basal border convex, and apical or masticatory border without teeth or denticles.

Thorax in profile strongly convex, promesonotal suture, meso-metanotal and the meta-epinotal sutures distinct, de-

${ }^{1}$ Published with a grant from the Museum of Comparative Zoology at Harvard College. 
spite the heavy sculpturing of the body. Epinotum with broadly rounded basal face passing abruptly into a deeply concave declivity which partially accommodates the nodelike petiole. The declivity is bounded laterally by high, sharp, narrow ridges, each ridge having a very small, blunt epinotal spine, that almost blends with the general sculpture. Petiole subglobose or nodiform, narrower in front, expanding gradually behind, but sharply constricted where it joins the postpetiole or first gastric segment; convex dorsally and concave ventrally, provided with a long, flat, anteriorly

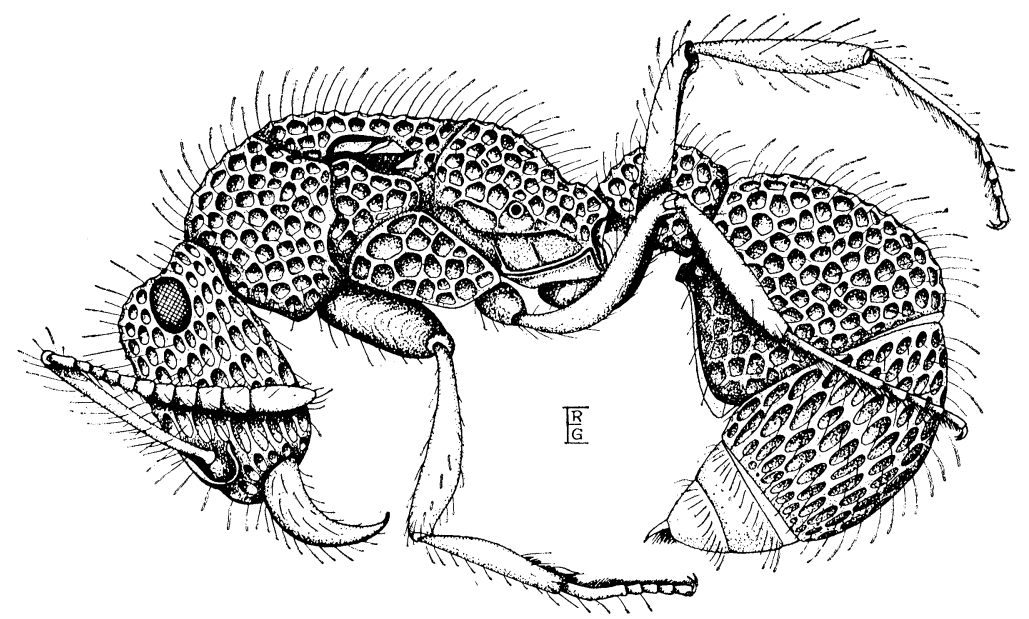

Text-fig. 1. Stictoponera posteropsis, profile.

projecting, ventral tooth. Postpetiole broad, globose, its ventral surface armed with a long, narrow keel which expands into an open, lip-like structure at the anterior margin and directly beneath the petiole. Remainder of gaster smaller than the postpetiole, and projecting downward and forward, and supplied with a well developed sting.

Wings hyaline, straw-colored, extending beyond the tip of the gaster. One cubital cell, one discal cell, one large and one very small submarginal cell, is each present in the forewing.

Head, dorsal aspect of mandibles, thorax, petiole, post- 
petiole, and the first segment of the gaster, completely and heavily sculptured with coarse, deep pits or foveolae. The pits are rounded to hexagonal on most of the body, but are elongate and oval on the head and the gastric segment. The sculpture is so coarse that under the microscope the shining surfaces, especially of the ridges between the pits are not diminished, but to the unaided eye, the general body tone is subopaque.

Long, delicate, sharp-pointed hairs cover all parts of the body and appendages, and arise separately from the foveolae where these are present. Pubescence is practically absent on the body, but is abundant on the scapes, funiculi, coxae, $\operatorname{legs}_{\mathrm{s}}$ and the posterior region of the gaster.

Color reddish brown, with the funiculi, scapes and legs a lighter red; tip of gaster yellowish.

Holotype: winged female (M.C.Z. No. 28556).

This species is described from a single female specimen (worker caste unknown), taken on November 12, 1921 at Wai Lima, Prov. of Lampong, southern Sumatra, by H. H. Karny.

The ant belongs apparently to a rare group, and, according to Dr. Brown, there is only one other specimen in the Wheeler Collection very similar to it, a worker taken by Dr. Chapman in the Philippines. This worker was marked as new by Wheeler, but was left undescribed. The new species finds its place among other Stictoponera (namely, rugosa (F. Sm.), coxalis Rog., menadensis Mayr, bicolor Em., and avia Forel), a group which possesses a low, loaf-shaped or globular petiole. None of these, however, has the eyes so far back on the head as does posteropsis, a character which alone will distinguish it from the others. I have seen a specimen of Stictoponera bicolor, and two of S. costata Sm. (=Ponera rugosa F. Sm.?), and upon comparing them with posteropsis, have found that the latter differs from them in the following particulars. The eyes are not only placed far posteriorly on the head, but are very convex, whereas in bicolor they are much flatter. The antennal scapes reach or project but slightly beyond the occipital corners, though in bicolor they exceed the corners by a distance equal to the greatest width of the scape. No teeth are present on the 
mandibles, but minute denticles are present on those of costata; frontal carinae have broad lateral lobes, but this condition is absent in bicolor. The humeral angles seem to be less sharp and projecting than in either costata or bicolor, and the epinotal spines are practically absent, though they might prove to be present on the worker when it is found. The sculpture is similar to that of the other two species, but shows the first gastric segment to have elongate and oval foveolae, whereas on costata they resolve themselves into very long grooves running the full length of the segment, and in bicolor the sculpturing on this segment is almost completely absent, leaving the surface smooth and shining. The ventral blade on the petiole is rounded while in costata its apical edge is notched, and a midventral keel or ridge is present on the postpetiole of posteropsis, this structure being absent on the other species. The comparisons made are between a female and the worker caste of the other species, but the differences are sufficiently striking to support the description of a new form. In addition, there are important differences in size; posteropsis ( $Q$ ), is slightly over $5 \mathrm{~mm}$. in length, costata ( $Q$ ), is over $8 \mathrm{~mm}$., and bicolor ( $Q$ ), is over $5 \mathrm{~mm}$. Although these ants are ponerines, undoubtedly, the worker of posteropsis, if known, would prove to be considerably less than $5 \mathrm{~mm}$. long.

\section{Camponotus (Myrmostenus) cooperi n. sp.}

Female. Length, $6.25 \mathrm{~mm}$., cephalic index, .55

Head, excluding the mandibles elongate, as indicated by the head index; rectangular in general shape, the widest point at the anterior angles where the mandibles articulate. Occipital angles abrupt, and posterior margin straight. Sides of head slightly concave, with the eyes medium sized and almost flat, located midway between the anterior and posterior ends. Ocelli about midway between the eyes and posterior border of the head. Clypeus convex, and produced anteriorly into a cone-like process. Frontal carinae low and indistinct, leaving the antennal insertions exposed. Antennae 10-segmented, scapes short, extending posteriorly only as far as the eyes; narrow at the base and expanding abruptly toward the apex. Funiculi gradually increasing 
toward the tips, the last three segments considerably enlarged, and each longer than broad, but not forming a club. Mandibles narrow, each with three apical teeth and one indistinct denticle.

Thorax long and narrow, gradually widening to the insertions of the forewings and tapering posteriorly from that point. Prothorax from above long and somewhat resembling a truncated isosceles triangle; mesothorax about as wide as long. Thorax in profile convex; pronotum flat but sloping upward to the mesonotum which is angled just behind the promesonotal suture; scutellum raised. Sides of thorax flat. Epinotum without distinct basal and declivious faces, the entire dorsum sloping away rapidly from the

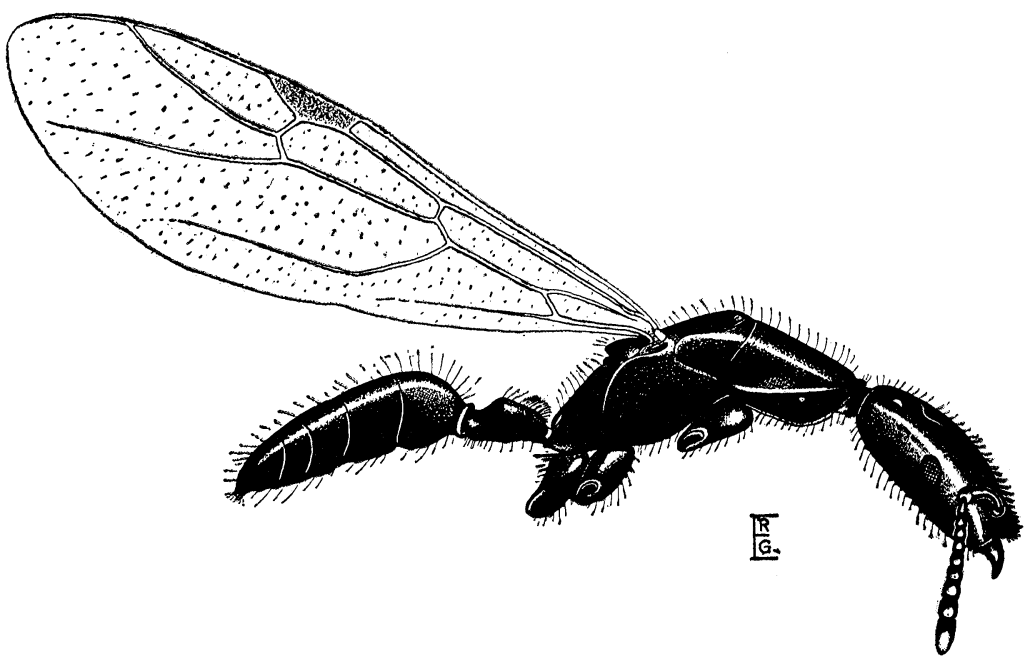

Text-fig. 2. Camponotus (M.) cooperi, profile.

metanotum to the articulation with the petiole. Petiole convex, low in front and rising gradually to a low broad node (no scale), whose posterior slope is concave; ventral surface smooth. From above, the petiole is rounded and almost oval in shape, though narrower in front and widening gradually to the apex of the node.

Gaster long, narrow, flat above, modified elliptical in 
shape, widest in the middle of the first segment, and tapering to a pointed posterior end. Entire body notably elongated and depressed.

All surfaces glabrous, very smooth and shining, the only indication of sculpture being the minute pits from which the hairs arise and a slight shagreening of the gaster. Hairs delicate, pointed, pale yellow, and present on the head, thorax, petiole, gaster, scapes, funiculi, and all segments of the legs. Pubescence very sparse but present on most surfaces; slightly denser on the gaster and thickest on the funiculi.

Forewing $5.4 \mathrm{~mm}$. long, with one cubital cell and no closed discal cells; brownish in color.

Color of body black throughout, except tarsi, articulations of legs and antennae, and the mandibles which are dark reddish brown.

Holotype: winged female (M.C.Z. No. 28555).

Described from a single specimen collected by Dr. Kenneth Cooper at Turrialba, Costa Rica. Attached to it is the number Cr $49 \mathrm{~F} 13$.

In 1903 Emery described Camponotus mirabilis, and later (1911), described two new species, C. sphenocephalus, and C. longipilis, with its variety $C$. l. postangulata, belonging to the same group. To-date these seem to be the only forms known, and are all from Peru. Emery placed these ants in the subgenus Myrmostenus in 1920, and they are so listed in the Genera Insectorum (1925, Fasc. 183, p. 161). They have in common a very large size, $16 \mathrm{~mm}$. or more, with very straight and elongated bodies and for the most part shining surfaces, giving them a striking appearance. The new species differs from all these in its much smaller size and its color which is practically solid, shining black. Despite this, it appears to belong in the subgenus and to represent a diminutive type. As all forms of Myrmostenus are known only as females, it has been suggested that the workers when found will show them to be members of some other group of Camponotus, and although this was mentioned by Emery, it has so far not been demonstrated; consequently, the conclusion that these ants form the subgenus Myrmostenus, for the present must rest. The new ant from Costa Rica is 
certainly distinct from the others and deserves to be recorded. No others in the subgenus have been described, as far as I am aware, since 1925 when Emery listed the then known species.

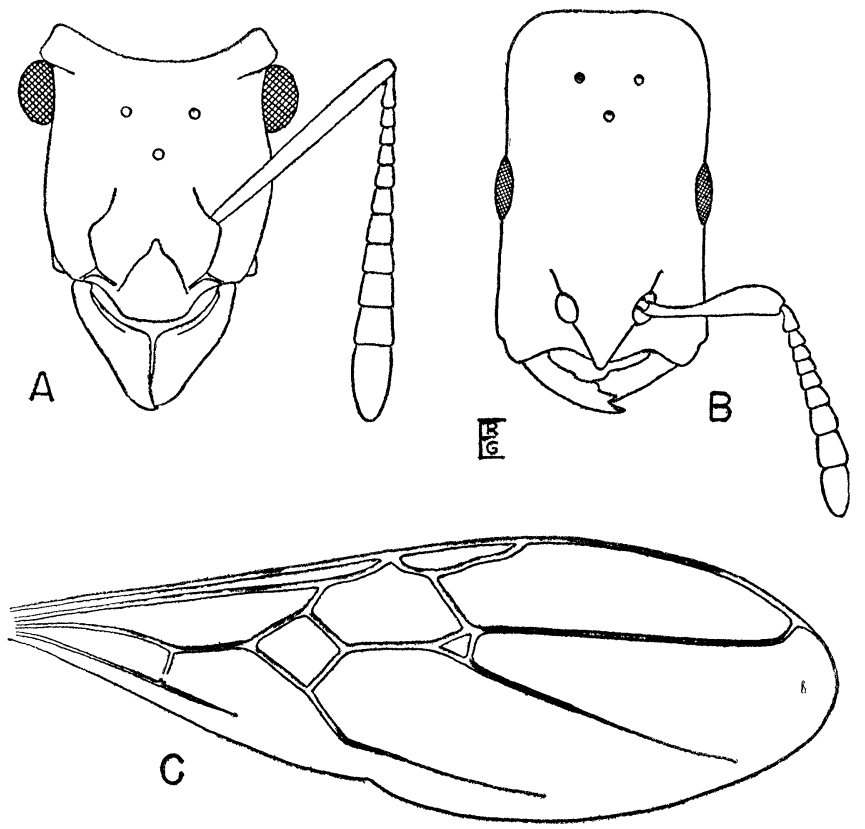

Text-fig. 3. A. Stictoponera posteropsis, head. B. Camponotus (M.) cooperi, head. C. Stictoponera posteropsis, wing.

Camponotus cooperi differs from its above named relatives, which are elephantine by comparison, in a number of additional particulars. The head, though elongate, is not concave on the occipital margin, as in mirabilis, and the sides are straight to slightly concave, not converging posteriorly as in sphenocephalus. The eyes are placed in the middle of the head and very much to the sides, whereas in mirabilis they are moved partially to the dorsal surface. The frontal carinae converge to a blunt point on the anterior margin of the clypeus, the antennae are inserted quite near 
the anterior end of the head, and the scapes which are short, are greatly thickened, and do not reach beyond the level of the eyes. The mandibles have three teeth (not 7). The sculpture is almost absent, the whole body being very smooth.

Dr. Brown has compared the ant with types of mirabilis in the Wheeler Collection, and assures me there is every reason to consider it a new form. He states: "I am practically certain that no species of this subgenus has been described since the end of the war (1945 on). It should be described as new, since Myrmostenus, whether or not it is the female of some other subgenus, is very little known, and not recorded outside South America so far as I can tell."

REFERENCES

EMERY, C.

1911. Fragments myrmécologiques. Ann Soc. Ent. Belg. 55: 213-225.

1925. Genera Insectorum. Fasc. 183. Subfam. Formicinae. 

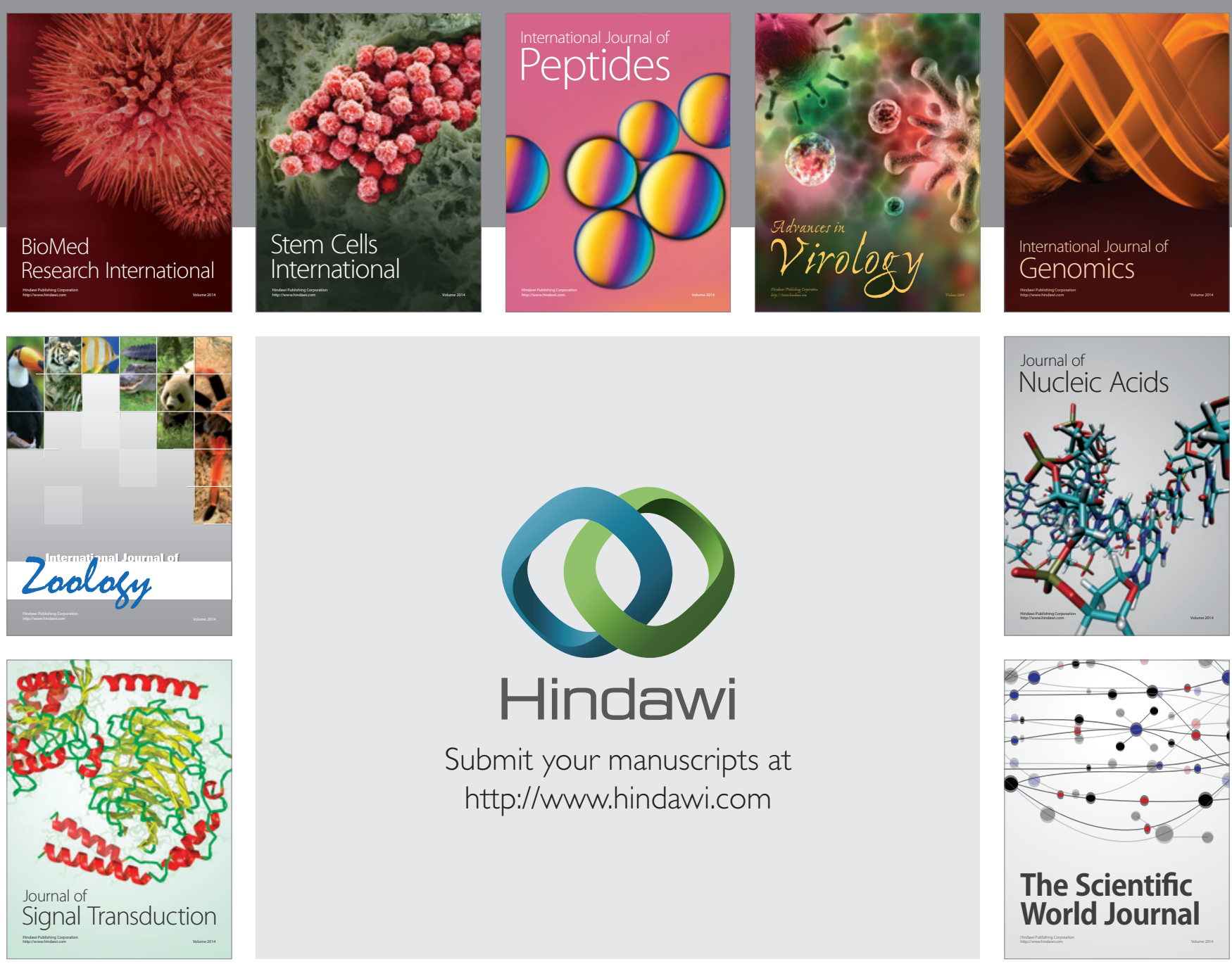

Submit your manuscripts at

http://www.hindawi.com
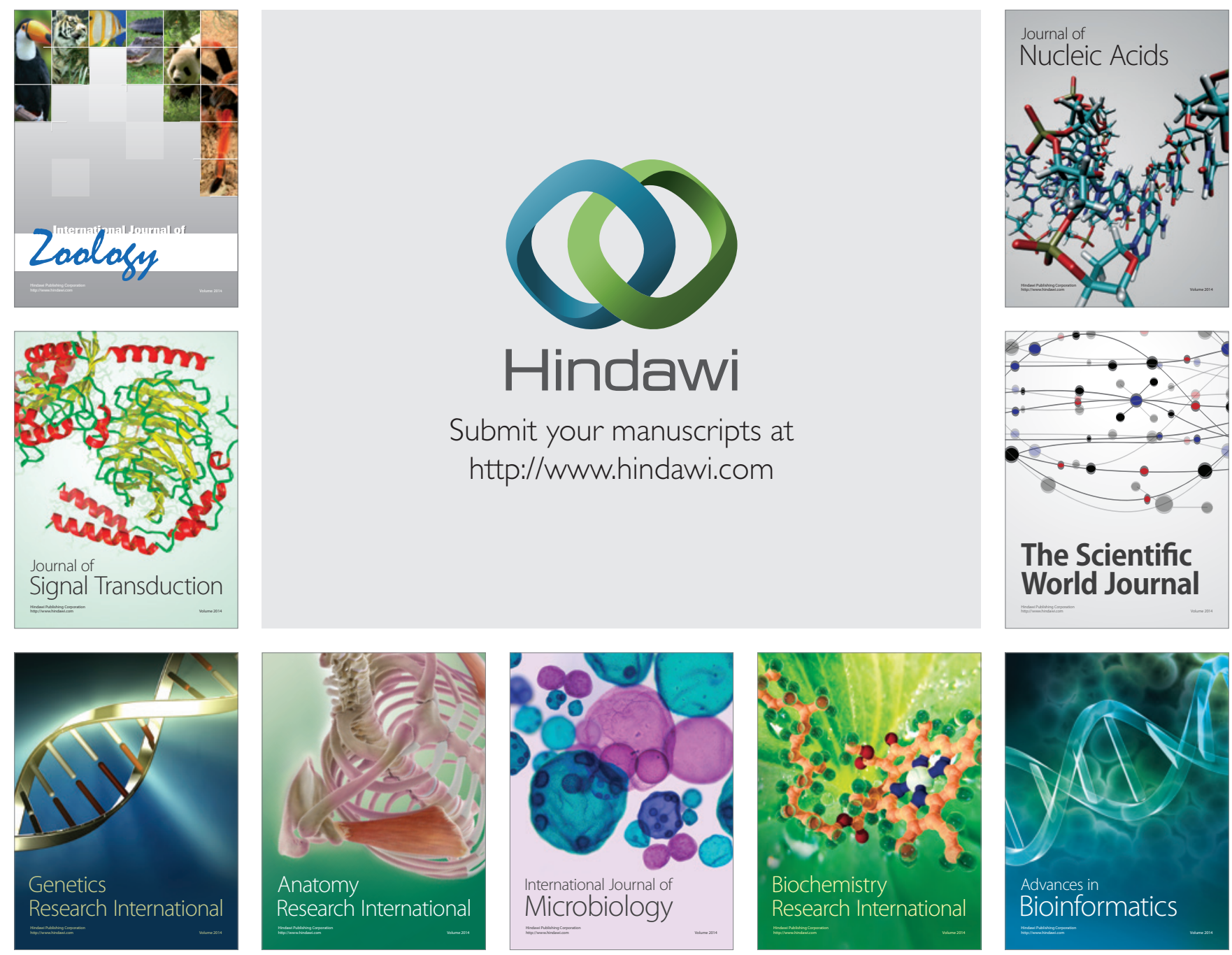

The Scientific World Journal
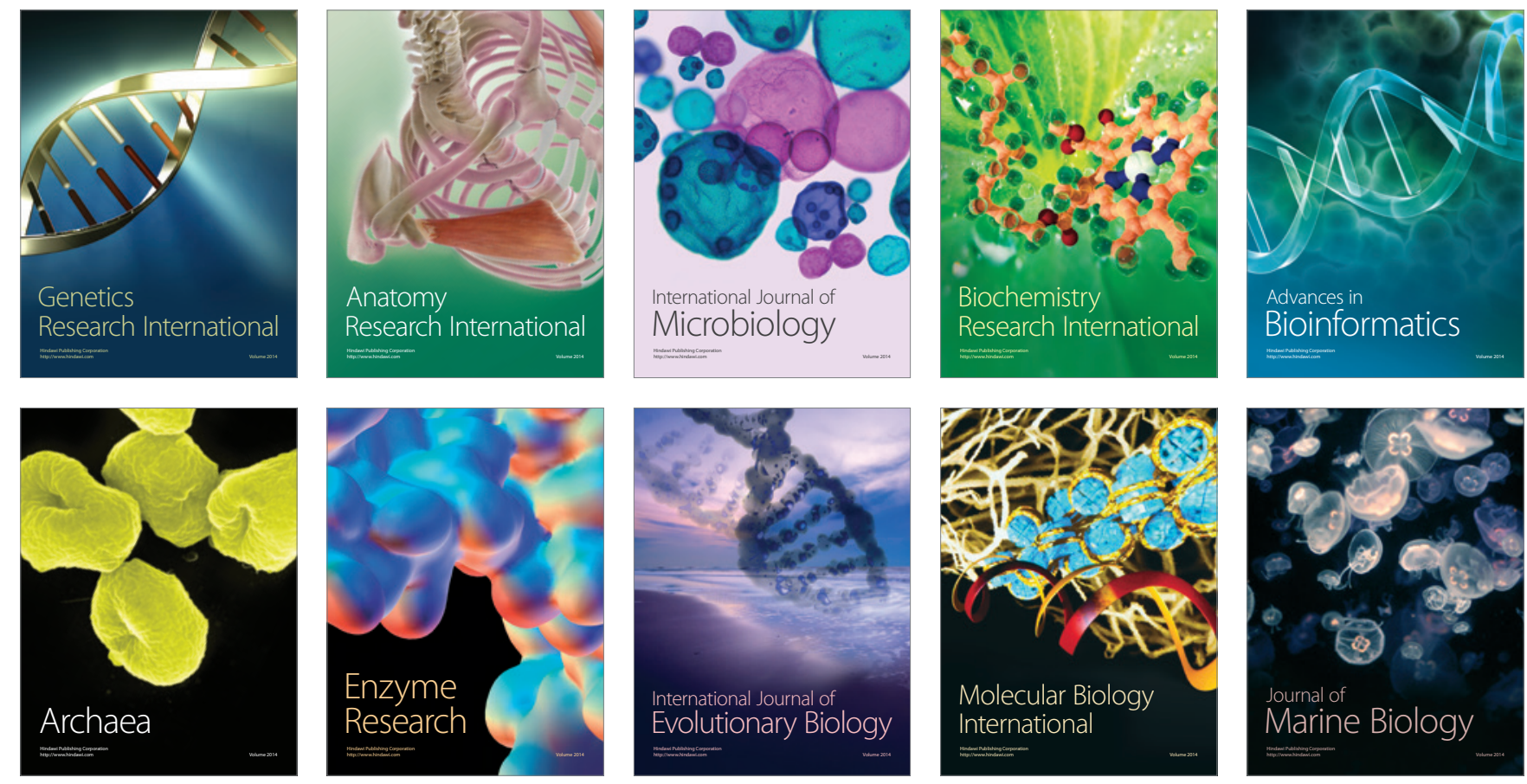